\title{
COLORECTAL CANCER; SITE DISTRIBUTION
}

1. Senior Registrar

Rehman Medical Institute, Peshawar

2. District Surgeon

RHC Gara Tajik, Peshawar

3. Junior Registrar Surgical C,

Lady Reading Hospital, Peshawar.

Correspondence Address:

Dr. Muhammad Fahd Shah.

House \# 103, Street 7, G 2,

Phase II, Hayatabad,

Peshawar, KPK, Pakistan.

dr_fahdshah@hotmail.com

Article received on:

25/03/2015

Accepted for publication:

15/03/2016

Received after proof reading: 26/05/2016

\section{Dr. Muhammad Fahd Shah', Dr. Irum SabirAli ${ }^{2}$, Dr. Ahmed Faraz ${ }^{3}$}

\begin{abstract}
Introduction: Colorectal cancer is a potentially fatal gastrointestinal disease and has been studied extensively. In an effort to decrease the morbidity and mortality associated with this disease, studies have been performed to gain insight into the anatomic distribution, average age at presentation, mean age at presentation for different segments of colon involved and intersex differences. Objective: The objective of this study is to determine the frequency of sites of colorectal cancer involvement. Material and methods: Study design: Study was descriptive case series. Setting: General surgical department post graduate Lady Reading Hospital Peshawar. Period: From 01/01/2011 to 30/06/2012. Sample size: Sample size was 416 using $3.57 \%$ proportion of descending colon ${ }^{5}$, 95\% confidence level and $1.785 \%$ margin of error under WHO software for sample size determination. Sampling technique: Consecutive non probability sampling. Results: This study was carried out in 416 consecutive patients. These patients included 233 men $(56 \%)$ and 183 women (44\%). Age varied from twelve years to seventy years. The commonest age group in the study at the time of presentation was6372 years. Commonest site involved was rectum $(26 \%)$ followed by sigmoid colon $(16 \%)$. Bleeding per rectum was the commonest symptom $(62.05 \%)$ followed by altered bowel habits (35.71\%). Twelve patients $(21.43 \%)$ presented with intestinal obstruction. Histopathologically, twenty patients had well differentiated adeno-carcinoma (35.72\%) whereas eighteen patients had anaplastic tumour (32.14\%) and mucinous adeno-carcinoma was found in five patients (8.92\%).Conclusion: Rectum is the most common site of tumour followed by left, right and transverse colon respectively. The site of involvement affects the surgical procedure required. In conclusion the symptoms of colorectal cancer may not be representative of any anatomical site, by the time symptoms appear the lesion may have become invasive.
\end{abstract}

Key words: Colorectal carcinoma, Colon, Malignancy, Anaplastic, Histopathology, Colonoscopy, Site.

Article Citation: Shah MF, Ali IS, Faraz A. Colorectal cancer; site distribution. Professional Med J 2016;23(6):687-692. DOI: 10.17957/TPMJ/16.2863

\section{INTRODUCTION}

Colorectal cancer has been studied extensively and is found to be a potentially fatal gastrointestinal disease. At present colorectal cancer is the $3^{\text {rd }}$ leading cause of cancer death as reported in the western population. ${ }^{1}$ Colorectal cancer is a disease that can be treated effectively with planned screening strategies and management. ${ }^{2}$ In an effort to decrease the morbidity and mortality associated with CRC, studies have been performed to gain an insight into the anatomic distribution, average age of presentation, mean age of presentation for different segments of the colon involved and intersex differences of the disease. $^{3}$
Several investigators have looked at the anatomical distribution of colorectal cancer in different ethnic groups in the United States. Blacks have been found to present with a high occurrence of right sided lesions, Asians primarily rectal lesions and whites have a high occurrence for left sided lesions. Recent studies have shown that right sided colorectal cancers are more likely to present at older age. ${ }^{4}$ It has also been suggested that the incidence of colorectal cancer is lower in women than in men. Other researchers have looked at the intersex differences in the segment involved in colorectal cancer and it was demonstrated that women have a high frequency of right sided lesion while men have a greater risk for rectal cancer. 
In the past two decades several western clinicians have noted an anatomic shift of distribution of colorectal cancer more towards the right side of colon. Some investigators have concluded that patients with right sided cancers are older than those with distal colorectal cancer. Women on the other hand made up a higher percentage of patients with proximal colon cancer. ${ }^{6,7}$

Since the implication of changing the anatomic distribution of colorectal cancer is important as regards both to etiology and detection, it is therefore important to ascertain any significant change in the distribution of colorectal cancer in this oriental society.

This study will help in highlighting the difference in the site of colon most commonly involved in the malignancy in our part of the world as compared to other Asians, Europeans and United States population. This study will also help in minimizing specific workup in patients who have colonic symptoms which in turn will help reduce the cost on the workup involved. Age is another factor which will be highlighted in the current study in order to make us aware of common age group carrying the colonic malignancy.

\section{Objective}

The objective of this study is to determine the frequency of common sites of colorectal cancer.

\section{MATERIAL AND METHODS}

\section{Study design}

Study was descriptive case series.

\section{SETTING:}

General Surgical Department Post Graduate, Lady Reading hospital Peshawar.

\section{Duration}

From 01/01/2011 to 30/06/2012.

SAMPLE SIZE:

Sample size was 416 using $3.57 \%$ proportion of descending colon $^{5}$, 95\% confidence level and $1.785 \%$ margin of error under WHO software for sample size determination.

\section{Sampling technique}

Consecutive non probability sampling.

\section{Sample selection}

Inclusion criteria

1) All patients presenting with fresh bleeding per-rectum and tenesmus with lesions on barium enema and colonoscopy and subsequently confirmed by histology.

2) Age of Patients above 12 years and included both male and female.

\section{Exclusion criteria}

1) Cancer of appendix as surgically, appendix is not considered to be part of colon and the common tumor of appendix is carcinoid.

2) Cancer of anus as it can have squamous cell carcinoma which was not part of my study was excluded by per rectal examination and proctosigmoidoscopy.

3) Secondary tumors (primary elsewhere) were excluded on the basis of history and previous medical records.

The above mentioned conditions act as effect modifier and if included would introduce bias in the study results.

\section{DATA COLLECTION PROCEDURE}

Ethical approval to conduct this study was obtained from IREB (institutional Research and Ethical Board) of the hospital. All patients meeting the inclusion criteria were included both from the outpatient department and emergency. The diagnosis of colorectal carcinoma was based on history of fresh bleeding per rectum withtenesmus, poor appetite and histopathological report confirming malignancy. Written informed consent, explaining the purpose and benefits of study to the patients, was taken along with maintaining strict confidentiality.

General information about the patient like age, gender and address were recorded. Complete physical examination was conducted followed by systemic examination especially abdominal and 
per rectal examination for any palpable mass or bleeding. Routine investigations like Full Blood Count, Urea, Serum Creatinine and Electrolytes, Liver function tests and screening for hepatitis $B$ and $\mathrm{C}$ were done. After a good bowel preparation of the patient by giving laxatives and clear fluids, specific investigation like barium enema and colonoscopy with biopsy of the lesion were undertaken by an expert with at least five years' experience to determine the site of lesion whether right, transverse, left or rectal. All biopsy specimens were sent to an expert histopathologist for confirmation of colorectal cancer.

Data was collected on a proforma. Strict exclusion criteria were followed to control confounder and bias in the study results.

\section{DATA ANALYSIS PROCEDURE}

Collected data was analyzed by using SPSS version10. Mean \pm standard deviation was calculated for quantitative variable like age of patients. Frequency and percentage was calculated for qualitative/categorical variables like gender and site of the lesion. Results were presented as tables, bars and pie charts.

\section{RESULTS}

The study was carried out on 416 consecutive patients presenting with large bowel symptoms. These patients included 233 men (56\%) and 183 women $(44 \%)$. Mean \pm SD of the patients was 48.9 (13.41) years.

Age varied from twelve years to seventy two years. Most common age group at presentation was $60-69$ (26.44\%) followed by age group 50-59 (24.76\%).

A total of fifty-six patients were confirmed as having colorectal carcinoma, thirty patients were male and twenty-six were female.

Age distribution of CRC is presented in (Table No-I). Mean age + SD of patients with cancer was 65.7 (5.99\%). Commonest site involved was the rectum $(51.78 \%)$ followed by left sided colon including the sigmoid (32.1\%) (Table No-II).
No difference in age of the patients of rightsided and left-sided cancers or their gender was observed. Associations between symptoms with endoscopic findings on total colonoscopy were assessed by a logistic regression model. None of the symptoms was a predictor for cancer. This result was the same even after adding age, gender and duration of the symptoms in analysis.

Bleeding per rectum was the commonest symptom (100.00\%) followed by tenesmus (100.00\%). Twenty patients $(35.71 \%)$ presented with altered bowel habits.

Histopathologically, twenty patients had well differentiated adeno-carcinoma (35.72\%) whereas eighteen patients had anaplastic tumour $(32.14 \%)$ and mucinous adeno carcinoma was found in five patients (8.92\%).

\begin{tabular}{|c|c|c|}
\hline Age Group & No of cases & \%age \\
\hline $\mathbf{1 2 - 1 9}$ years & 02 & $3.58 \%$ \\
\hline $\mathbf{2 0 - 2 9}$ years & 10 & $17.8 \%$ \\
\hline $\mathbf{3 0 - 3 9}$ years & 07 & $12.7 \%$ \\
\hline $\mathbf{4 0 - 4 9}$ years & 06 & $10.72 \%$ \\
\hline $\mathbf{5 0 - 5 9}$ years & 17 & $30.35 \%$ \\
\hline $\mathbf{6 0 - 6 9}$ years & 14 & $25 \%$ \\
\hline Total & 56 & $100 \%$ \\
\hline Table-l. Age distribution of CRC cases $(n=56)$ \\
\hline
\end{tabular}

\begin{tabular}{|l|c|c|}
\hline \multicolumn{1}{|c|}{ Site } & No. of Cases & \%age \\
\hline Rectum & 29 & $51.78 \%$ \\
\hline Left sided & 18 & $32.14 \%$ \\
\hline Transverse colon & 01 & $01.79 \%$ \\
\hline Right sided & 08 & $14.29 \%$ \\
\hline Total & 56 & $100 \%$ \\
\hline \multicolumn{2}{|c|}{ Table-II. Site of involvement $(\mathrm{n}=56)$} \\
\hline
\end{tabular}

\section{DISCUSSION}

It was thought that people of the Asian subcontinent, having predominant vegetarian dietary habits, were protected from developing colorectal cancer. ${ }^{8}$ This does not hold true. Studies show a substantial increase in the number of patients of colorectal cancer, particularly the incidence at younger age, as almost the same as in high-risk group of patients of the West. ${ }^{8,10}$ Family history 
of Familial Polyposis Coli, a family history of colon cancer or a history of inflammatory bowel disease were not found to correlate in my study whereas, significant correlation has been found in the studies from the west. ${ }^{11,12}$ Rectal bleeding and pain were the presenting symptoms in most of our patients of colorectal malignancy followed by symptoms of recent changes in bowel habits. These findings are comparable with other studies as well. ${ }^{10,13,14,15}$

More than $50 \%$ cases of the carcinoma presented in the rectum and sigmoid region in this study. Studies from different regions have documented almost similar figures regarding the location of the malignancy. $8,10,15,16$

Histopathology of the majority of tumours of our patients showed well differentiated and moderately differentiated tumours whereas, O'Connell ${ }^{17}$ study has reported that more than $50 \%$ of patients with CRC suffer from moderately or poorly differentiated tumours.

Colorectal cancer incidence by populationbased cancer registries shows a wide variability. Geographical and ethnic differences have been observed. CRC is the $4^{\text {th }}$ most common cancer in Iran with an annual incidence rate of 6 to 7.9 per 100,000 of the population. However, annual ASR (to world population) is estimated to be 6.7 in males and 5.2 in females in our region ${ }^{18}$ and Pakistan remains a low risk region for colorectal cancer. Conversely; upper gastrointestinal cancer is the most common cancer in our region, with high mortality and morbidity.

In contrast to low incidence of $\mathrm{CRC}$ in youngage within western countries (2-8\% younger than $40)^{19}, 15-35 \%$ of CRC patients in Middle East and $17 \%$ in Iran are under $40^{20}$. There has been much discussion about the anatomic distribution of colorectal tumours. A "left" to "right" sided or proximal shift of tumours has been reported in studies mostly from the USA. ${ }^{21,26}$ Nevertheless, several other studies have shown no such shift. ${ }^{27,31}$

In the current study majority of polyps (51.7\%) were located in the recto-sigmoid/anal region Some previously published studies showed older age of patients with right-sided tumours. However, No difference in the age of diagnosis of right-sided and left-sided tumours was observed in our patients, in line with one other study. ${ }^{32}$ Determination of tumor type is critical because different tumor types vary regarding their radiosensitivity, local behavior, and propensity for regional and systemic metastasis. In the UK more than $90 \%$ of cases are adenocarcinoma and the vast majority arise from adenomas, either flat or polypoidal. ${ }^{33}$ These common benign tumors develop from normal colonic mucosa and are present in about a third of the European/ USA population. Histopathologically, reports in our study showed highest percentage to be adenocarcinoma patients i.e. in 47 (83.9\%). This is also in accordance with the results of a local study conducted at the Aga Khan University Hospital, Karachi which showed that colorectal adenocarcinoma was found in $71.76 \%{ }^{34}$ patients

In another local study by Malik KA, 35.72\% patients had well differentiated adeno- carcinoma whereas $32.14 \%$ patients had anaplastic tumor and mucinous adeno carcinoma was found in 8.92\% patients (361). In another adenocarcinoma group, non-mucinous type was predominant than mucinous type in our study .In a local study $59 \%$ were reported as non-mucinous adenocarcinoma, $30 \%$ as mucinous adenocarcinoma and $11 \%$ as signet-ring cell type carcinoma. ${ }^{35}$ The nonmucinous adenocarcinoma has been noted to be the common histological type of CRC in other countries as well. In a study 2079 patients diagnosed with colorectal cancer between 1994 and $2007,1837(88.35 \%)$ patients were having non mucinous adenocarcinoma, 144(6.92\%) had mucinous and $25(1.20 \%)$ had signet-ring cell. ${ }^{36}$ In a study 8172 lesions, the mucinous adenocarcinoma was noted in $800(12.3 \%)$ and signet ring cell carcinoma in 51(0.8\%) lesions. Also the frequency of carcinoid tumour was in $22(0.3 \%)$, squamous carcinoma in $21(0.3 \%)$, adenosquamous carcinoma in $9(0.1 \%)$, and other types in 95 (1.46\%) lesions. ${ }^{37}$ 


\section{CONCLUSION}

Rectum is the most common site of tumour followed by left, right and transverse colon respectively. Altered bowel habits and blood in the stools are very common presentation with colorectal carcinoma especially in patients with advance age. The segment of the colon involved affects the outcome of treatment and the workup required. Rectal lesions have usually obstructive symptoms and therefore detected early. Right sided lesions on the other hand have been reported as large with no obstructive changes but patients present with anaemia. The site of involvement also affects the surgical procedure required. The physical findings of rectal mass underscore the utility of complete physical assessment during abdominal examination. Early colorectal investigations for patients with rectal bleeding, a change in bowel habits and anaemia may improve the outcome. Screening colonoscopy offers the potential to both identify the site and remove cancers and premalignant lesions throughout the colon and rectum. Studies have been carried out to show reduction in mortality associated with screening colonoscopy. Copyright(C) 15 Mar, 2016.

\section{REFERENCES}

1. Chan AT, Giovannucci EL. Primary Prevention of Colorectal Cancer. Gastroenterology. 2010;138(6):2029-43.

2. Yang VW, Lewis J, Wang TC, Rustgi AK. Colon Cancer: An Update and Future Directions. Gastroenterology. 2010;138 (6):2027-8.

3. Rozen P, Rosner G, Liphshitz I, Barchana M. The Changing Incidence And Site Of Colorectal Cancer In The Israeli Arab Population and There Clinical Implications. Int J Cancer. 2006;120:147-51.

4. Shavers VL. Racial/Ethnic variation in the anatomic sub site location of in situ and invasive cancers of the colon. J Natl Med Assoc. 2007;99(7):733-48.

5. Malik KA. Colorectal Carcinoma: A six years' experience at a tertiary care hospital of sindh. JLUMHS. 2007;11:74-6.

6. Gellag ZF, Provenzale D. Colorectal cancer: National and international perspective on the burden of disease and public health. Impact. 2010;138(6):217790.
7. Rim SH, Seeff L, Ahmed F, King JB, Coughlin SS. Colorectal cancer incidence in United States, 19942004: an updated analysis of data from National Program of Cancer Registries and Surveillance, Epidemiology, and End Results Program. Am Cancer Society. 2009;115(9):1967-76.

8. Al-Jaberi TM, Yagha RJ, El-Heis HA. Colorectal cancer in young patients under $\mathbf{4 0}$ years of Age; comparison with old patients in a well-defined Jordanian population. Saudi Med J. 2003;24(8):871-4.

9. Sing $Y$, Vaidya P, Hemandas AK. Colorectal carcinoma in Nepalese young adults, presentation and outcome. Gan kagaku Ryoho. 2002;29:223-9.

10. El-Henna WY, Mousa ME, El-Saeidy MK. Rectal cancer in Egyptian patients less than $\mathbf{4 0}$ years of age. Int Surg. 2003;88(3):137-44.

11. Chiang JM, Chen MC, Chang CR, Chen JS. Favorable influence of age on tumour characteristics of sporadic colorectal adenocarcinoma patients 30 years of age or younger may be a distinct patient group. Dis Colon Rectum. 2003;46(7):904-10.

12. Turkiwicz D, Miller B, Schache D, Cohen J. Young patients with colorectal cancer: how do they fare? ANZ J Surg. 2001;71(12):707-10.

13. Lin JI, Wang WS, Yen CC, Liu JH, Yang MH. Outcome of colorectal carcinoma in patients under 40 years of age. J Gastroenterol Hepatol. 2005;20(6):900-5.

14. Yiu HY, Whitemore AS, Shibata A. Increasing colorectal cancer incidence rates in Japan. Int $\mathrm{J}$ Cancer. 2004;109(5):777-81-9.

15. Rasul KI, Awidi AS, Mubarak AA, al Hamsi UM. Study of colorectal cancer in Qatar. Saudi Med J. 2001;22(8):705-7.

16. Kan MH, Eu KW, Barban CP. Colorectal cancer in the young: a 12 years review of patients $\mathbf{3 0}$ years or less. Colorectal Dis. 2004;6(3):191-4.

17. O'Connell JB, Maggard MA, Liu JH, Etzioni DA, Livingston $\mathrm{EH}, \mathrm{Ko} \mathrm{CY}$. Do young colon cancer patients have worst outcome? World J Surg. 2004;28(6):55862.

18. Ansari $R$, Mahdavinia $M$, Sadjadi. Incidence and age distribution of colorectal cancer in Iran: Results of a population-based cancer registry. Cancer Letters. 2005;40:143-7.

19. Axtell $L M$, Chiazze $L$. Changing relative frequency of cancers of the colon and rectum in United States. 
Cancer. 2003;19:750-4.

20. Bafandeh Y, Daghestani D, Esmaili H. Distributionof cancer and adenomatous polyps in the colorectum: studyin an Iranian population. Asian Pac $\mathrm{J}$ Cancer Prev. 2006;7:65-8.

21. Bombi JA. Polyps of the colon in Barcelona, Spain. Cancer. 1998;61:1472-6.

22. Colorectal cancer update: Prevention, screening, treatment, and 5surveillance for high risk groups. Med Clin North Am. 2000;84:1163-82.

23. Brenna E, Skreden K, Waldum HL. The benefits of colonoscopy. Scand J Gastroenterol. 1990;25:80-8.

24. Chao A, Thun M J, Connell CJ. Meat Consumption and Risk of Colorectal Cancer. JAMA. 2005;293:172-82.

25. Church JM. Clinical Significance of Small Colorectal Polyps. Dis Colon Rectum. 2004;47:481-5.

26. Correa P, Strong JP, Reif A. The epidmiology of colorectal polyps: Prevalence in New Orleanns and international comparisons. Cancer. 1997;39:2258-64.

27. Crerand S, Freely TM, Waldron RP. Colorectal carcinoma over 30 years at one hospital: no evidence of a shift to the right. Int J Colorectal Dis. 1991;6:1847.

28. Cucino C, Buchner AM, Sonnenberg A. Continued right ward shift of colorectal cancer. Dis Colon Rectum. 2002;45:1035-40.

29. Devesa SS, Chow WH. Variation in colorectal cancer incidence in the United States by the subsite of
origin.Cancer.1993;71:3819-25.

30. Fenoglio CM, Kaye GI, Pascal RR. Defining the precancerous tissue of ordinary large bowel carcinoma. Implications for cancer prevention. Path Ann Applet Cent Crofts. 2004;12:87-116.

31. Goh KL, Quck KF, Yeo GT. Colorectal cancer in Asians : a demographic and anatomic survey in Malaysian patients undergoing colonoscopy. Alimen Pharmacol Ther. 2005;22,859-64 .

32. Gomez D, Dalal Z, Raw E. Anatomical distribution of colorectal cancer over a $\mathbf{1 0}$ year period in a district general hospital: is there a true rightward shift? Postgrad Med J. 2004;80:667-9.

33. Malik KA. Colorectal carcinoma: a six years' experience at a tertiary care hospital of Sindh. J Liaqat Uni Med Health Sci. 2007;12:74-6.

34. Ahmad Z, Idrees R, Ahmed R, Kayani N, Pervez P, Hasan SH. Colorectal Carcinoma, extent and spread in our Population. Resection specimens give valuable information. J Pak Med Assoc. 2005;55:483-5.

35. Steel RJC. Disorders of the colon and rectum. In: Cuschieri SA, Steel RJC, Mossa AR, editors. Essentials surgical practice. London: Arnold, 2004.p.569-626.

36. Williams NS. The rectum. In: Russell RCG, Williams NS, Bulstrode CJ, editors. Bailey and Love's short practice of surgery. London: Arnold, 2004.p.1219-41.

37. Ries LAG, Eisuer MP, Kosary CL. Cancer statistics review 1975-2000, Bethesda: National Cancer Institute, USA. 2005.

\section{PREVIOUS RELATED STUDY}

Muhammad Akram, Wasim Amer, Javaid Iqbal. COLORECTAL CANCER; OVERALL SURVIVAL AND ITS PROGNOSTIC FACTORS, A RETROSPECTIVE ANALYSIS FROM 10 YEAR DATA FORM JHL. (Original) Prof Med Jour 16(4) 492-498 Oct, Nov, Dec 2009.

\section{AUTHORSHIP AND CONTRIBUTION DECLARATION}

\begin{tabular}{|c|l|l|}
\hline Sr. \# & \multicolumn{1}{|c|}{ Author-s Full Name } & \multicolumn{1}{|c|}{ Contribution to the paper } \\
\hline 1 & Dr. M. Fahd Shah & Paper writing \\
\hline 2 & Dr. Irum SabirAli & Data collection \\
\hline 3 & Dr. Ahmed Faraz & Data analysis
\end{tabular}

